\title{
The Propensity of Household to go on Vacation, Indonesia
}

\author{
Dwini Handayani, Sartika Djamaluddin \\ Faculty of Economic and Business \\ Universitas Indonesia \\ Depok, Indonesia \\ dwiniarianto@yahoo.com
}

\begin{abstract}
The propensity to go on a vacation for Indonesian family is predicted to increase. Despite this, every household will still consume leisure activities but how much it consume depends on its income and preference. It becomes important for the goverment not only to prepare and study who are the foreign tourist but also who are the domestic tourists. This study will calculate the propensity to go on vacation using the 2013 Socio Economic National Survey (SUSENAS) to learn the Indonesian household probability to go on vacation and its determinant. Using the probit method we could calculated households and their probability to go on vacation.
\end{abstract}

Keywords-Propensity, probability, vacation, determinan to go on vacation

\section{INTRODUCTION}

The propensity to go on a vacation for Indonesian family is predicted to increase. Mr Jokowi, the President of Indonesia mention during his visit to China, that Indonesia must choose a sector that embeded a comparative advantage. He mentioned that the tourism sector will be one of the engine of growth during his presidency. Vacation is a tertiery good, the consumption will increase when the household has fullfilled its day to day needs. Despite this, every household will still consume leisure activities but how much it consume depends on its income and preference. The increase in household propensity to go on a vacation also increases due to the decrease in transportation cost. It has also been enhanced by the globalization in information, part of it is information on tourist sites in the Country and even abroad. Household could choose destinations that fits their budget.

The Indonesian goverment has stated in their goverment decree number 5 year 2011 on The Nationla Tourism Development Master Plan 2020-2025 that to strangthen the tourism sector one elemen is to develop National Stretegic Tourim Region (Kawasan Strategis Pariwisata Nasional). This special region is expected to enhance economic, social, culture growth. But also to take account natural environmental sustainability. The Ministry of Toursm has set a target that the tourism sector will contribute 8 percent of the Product Domestic Brutto (PDB) . And also target that this sector will also absorb 13 million new workers. The goverment has also established 2 Special Economic Region (Kawasan Ecomini Khusus) in the Tourism Sector. And plan to develop 8 more similar Special Economic Region by 2019. The 2 region that has already established are Mandalika (West Nusa Tenggara Province) and Tanjung Lesung (Banten Province).

The contribution of the Tourism sector to the PDB is not as large as the Manufacture or the agriculture sector, but the goverment has notice as an archipelago Indonesia has millions and diverse of beautiful potential tourism areas. Tourism has slowly but stedily contribut to the economic growth and has open many job opportunities in all of the regios. The Central Berau of Statistic has calculated that in 2015 the Tourism sector has created 10.36 percent of the total 114.8 million of labor absorbed. This shows that the tourism sector has became not only the rising engine of growth but also created economics growth with large nurber of new job opportunities. Both are two important component needed by the Indonesia as it has reached the Demographic Deviden Period. A periode when the number of productive age is significantly higher than the elder and young population. This population structure is a potential era to achieve high economic growth, but comes with several preriquisites such as the poductive are working productively. Without these new jobs, the demographic deviden is an era where the composition of the productive age exceedes the nonproductive age.

Tourism is categorized as tertiery needs. The global pattern shows that going on vacation is no more tertiary priority but switch into a trend or lifestyle need. This is a result of changing population preference as a result of growth in commoon welfare and increase in travel avordability. The internet access has also boost this need, whereas people could seek areas at the other side of the world to plan to go and seek travel and accomodation cost that are avordable. Long working hours and high school activities has made vacation a need for families and friends to reconnect o relieve stress.Data shows that

Tourism has also flourish as the number of middle income increase. Investorpedia has mention several signs of middle income population that are home ownership, automobile ownership, colledge education for kids, retirement security, health care coverage and family vacation (McWinney, 2016).The number of middle income class in Indonesia is projected to be 2 percent. As this number increase, it can be concluded that the growth in tourism will also increase; domestic and international vacation destiny.

It becomes important for the goverment not only to prepare and study who are the foreign tourist but also who are the 
domestic tourists. Know Your Customer (KYC) is a key knowledge in how to prepare the tourism business. KYC could be done by knowing the demographic characteristic and the determinant in propensity to go on vacation.

\section{Study ObJective}

There has been little research on Indonesian household that go on vacation using secondary large data. To fill this research gap, the purpose of this study is to examine,

a. The probablitity of household to go on vacation

b. Investigating the determinants of household to go on vacation by level of income and other demographic characteristics.

\section{DETERMINATION OF PROPENSITY TO GO ON VACATION AND EMPIRICAL STUDIES}

Tourism as a tertiery needs will increase as the increase of nations welfare. Microeconomic theory on consumers choice's rule of thumb mentions that demand of a certain good will change as price and preference of consumers change. Venkatesh, Alladi (1990) stated that change pattern of consumption has micro and macro reasons. At the macro level, the chnage in environment such as the difference in land use could lead to a change in consumption pattern.Preference and taste change is one main reason in change in behavior.Urbanization and the increase in number of population categorized as middle income class has large impact on the aggregate demand of goods and services.

Pyndick (2012) that explains tradition theory in the determinant of demand of a good and services are price, change in income, taste, change in price of input or price of other goods and number of population. McKinsey (2012), from its survey has stated that the rise of the middle income class, has also shown a upward mobility trend. This upward mobility has changed their preference. The survey indicates that consumer has shown an increase in leisure and vehicles investment spending. Leisure or traveling to go on vacation has changed from being a tertiery good into a secondary good. Mckinsey (2012) also predicted that the anual growth of leisure spending will growth 7.5 percent in teh 2011-20130 period. This frowth rate is predicted to be higher that the health care and education spending that are to be around 6 percent.

The tourism is targeted and predicted to have a enhanced rate of growth not only among international tourist but also among domestic tourist.The World Economic Forum (2015) also stated that Indonesia's competitiveness has took a leap from the rank 70 in 2013 to the 50 rank in 2015. This leap in competitiveness is an result from the masive growth in infrastructure that has support the tourism sector, as an example the increase of coverage in celular network and transportation. To encourage and conduct proper policy, a targeted analysis on customer must be done in order to be able to provide pinpointed improvements. There are elements that must be addressed to be able to conduct this improvement correctly, that are customers needs, behavioral discrepancies and relational dimensions (Mullins et all, 2014). There dimensions are determined by the customers characteristics.
Spending are driven by "wants" but only could be materialized by their accesability, or constrained by their budget income. The higher the income then the higher their ability to fullfill their "wants".Consumption behaviour are also differentiated by these constraints, then tourism destination also differentiate. Those with higher income have higher ability than other income groups (Nicolau and Mas, 2005). They might have a preference to go on vacation at certain areas.

Kattiyapornpong and Miller (2008) stated that socio demographic variables such as age, income and life stage have large impacts on travel behaviour. But he found that there are significant increase on those with the highest constrain such as income. And these impacts differ and are specific for each countries. Life expectancy has increased in the deveoped countries, on the contrary the ability to save also increases another factor is increase in health. I other words increase in ability to travel financially and physically. On the contrary Romsa and Blenman in Kattiyapornpong and Miller (2008) stated that motivation for taking vacation vary by age group. Taking vacation as leisure declines with age. This condition is due to the phisical restricten that increases as age increases. Education also motivates household to go on vacation. The higher the education then the higher the awareness of household on the importance of having leisure time and encourage houdeholds to go on vacation. Education also develop curiosity about different culture, landscapes etc. This will rive the desire to go vacation outside of the house. Education also grow the knowledge of social status and knowledge on vacation as a symbole of status.

\section{METHOD}

This study will calculate the propensity to go on vacation using the 2013 Socio Economic National Survey (SUSENAS) to learn the Indonesian household probability to go on vacation and its determinant. Susenas is a nationaly representatif survey conducted by the Central Bureau of Statistic that provide information of socio econmic condition with a sampel of 300,000 households in 33 province.

This study uses the Probit Model. The probit model uses an asumption that there is an teoretical continous index $\mathrm{Z}_{\mathrm{i}}$ that is determinde by the explanatory variabel $\mathrm{X}_{\mathrm{i}}$,

$$
\mathrm{Z}_{\mathrm{i}}=\alpha+\beta \mathrm{X}_{\mathrm{i}}+\varepsilon, \quad \varepsilon \sim \mathrm{N}\left(0, \sigma^{2}\right)
$$

The data category $\mathrm{Z}_{\mathrm{i}}$ consist two values, 1 if the household goes on vacation and o for those who dont go on vacation. The model asumses that $Z_{i}^{*}$ follows a normally distributed random variable. $Z_{i}^{*}$ predicts the citical value that explains the decision of household to participate (go on vacation) or not.Household has a probability to participate (go on vacation) when the value $\mathrm{Z}_{\mathrm{i}}$ is larger or the same to the critical value $\mathrm{Z}_{\mathrm{i}}{ }^{*}$.

$$
\mathrm{P}(\mathrm{Z}=1)=\mathrm{P}\left(\mathrm{Z}_{\mathrm{i}} \geq \mathrm{Z}_{\mathrm{i}}^{*}\right)=1-\mathrm{F}\left(\mathrm{Z}_{\mathrm{i}}\right)
$$

In the probit model, the value $\mathrm{X} \beta$ is taken to be the $\mathrm{Z}$ - value of a normal distributon. Higher values of $X \beta$ means the event is more likely to happen. In the probit model we observe : 


$$
y_{i}=\left\{\begin{array}{l}
0 \text { if } y_{i}^{*} \leq 0 \\
1 \text { if } y_{i}^{*}>0
\end{array}\right.
$$

The cummulative normal probability function $\mathrm{F}\left(\mathrm{Z}_{\mathrm{i}}\right)$ follows:

$$
\mathrm{F}\left(\mathrm{Z}_{\mathrm{i}}\right)=\frac{1}{\sqrt{2 \prod}} \int_{-\infty}^{Z_{i}} e^{-\left(Z_{i}\right)^{2} / 2} d t
$$

The probit regression modelfor predicting the probability to go on vacation :

$$
\begin{aligned}
& y=\alpha_{1}+\alpha_{2} * x_{1}+\alpha_{2} * x_{1}^{2}+ \\
& \alpha_{4} * I+\alpha_{5} * A+\alpha_{6} * A^{2}+\alpha_{7} * G+\alpha_{9} * P+e
\end{aligned}
$$

The dependen variable of model is dummy variabel, 1 going to vacation, 0 others. The independen variables are $X_{1}$ is year of schooling (years), $\mathrm{I}$ is natural logarithm of income, $\mathrm{A}$ is age (years), $\mathrm{G}$ is dummy gender, 1 man, 0 other, $\mathrm{P}$ is dummy province, we classify 33 provinces into 6 grup based on the island. So we have 5 dummy namely sumatera, jawa, bali_nusa tenggara, kalimantan, sulawesi and maluku. The base is papua islandthat consist papua and papua barat. The characteristic of the household will be represented by the Household head's characteristics as he/she is the one deciding all non-day to day decisions.

\section{FINDINGS}

Data Susenas shows that the average household that goes on vacation in 2013 are those with the average monthly income of 2,204,154 rupiahs that is twice of the average of household income that do not go on vacation. Where as The Bank Indonesia has calculated that the average middle income class was araind 20.4 million rupiahs per year. This stregnthen the hypotesis that the rising middle income in Indonesia will also enhance the increase of tourism.Discriptively, figure 1 shows that the number of hoseholds that go on vacation are living in Java and Sumatera. This could be expected as the population is highly concentrated in Jawa and Sumatera. Vacation is a tertiery needs, as the income increases then the ability to fullfill this need will also increase. Enhance economic growth and increase in welfare as the decrease in transportation cost will also boost this sector in the future.

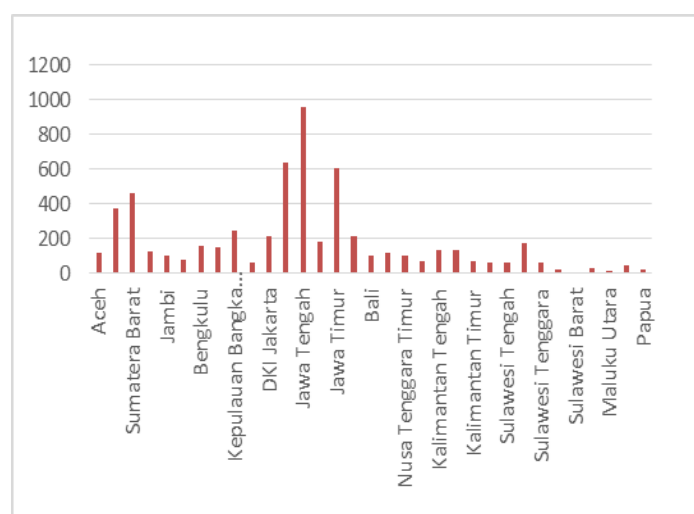

Fig. 1. Number Of Household Who Goes on Vacation. Source : Susenas 2013
However, figure 2 shows that the household that go on vacation averagely has lower income compared to those living in other Islands. The two figures shows that low income is not a barrier to go on vacation. Household can customize a vacation destination due to their budget constraint.

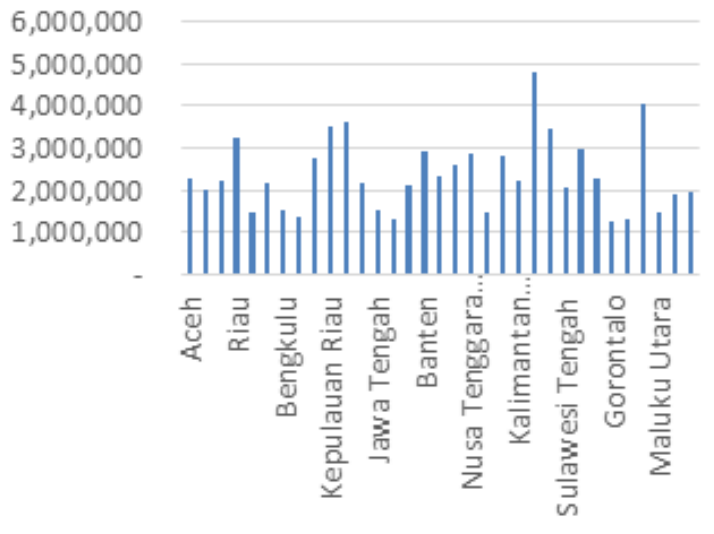

Fig. 2. Average Household Income Who Goes on Vacation by Province

Figure 3 describes that house show that number of household which are headed by women slightly higher then men. And the average age of those that go on vacation are headed those age 26. The higher the age of the household head probably the higher the responsibility. The average age to marry for Indonesian according to the 2012 Indonesian Demographic and Health Survey for men are aproximately 23 years old. Meaning if they the have children right away, then it will be more difficult physically and financially to allocate budget tp go on vacation. And probably become more difficult to alocate time to go on vacation.

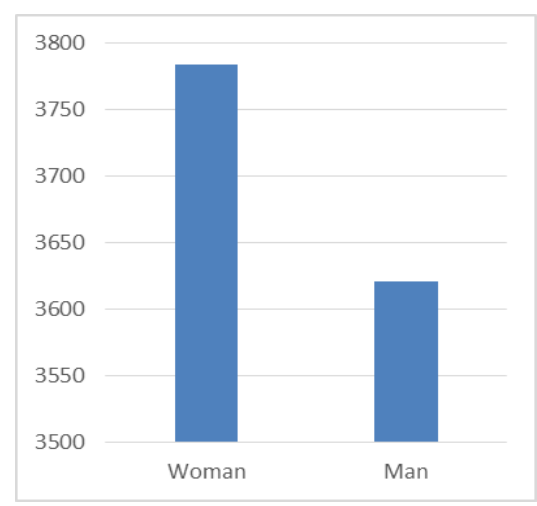

Fig. 3. Number Of Household Who go on acation by Household Head Gender. Source : Susenas 2013

Table 1 below shows result from the probit inferential. The model points out that income has positive effect on probability to go on vacation. The higher the income than the higher the probability of household to go on vacation. The increase of 1 percent in income will increase the probability 0,0062947percentage point. Household's ability to fullfill their basic needs and have additional budget for vacation will increase as income increase, and the probability to go on 
vacation will also increase. This in line with Nicolau and Mas findings (2005).

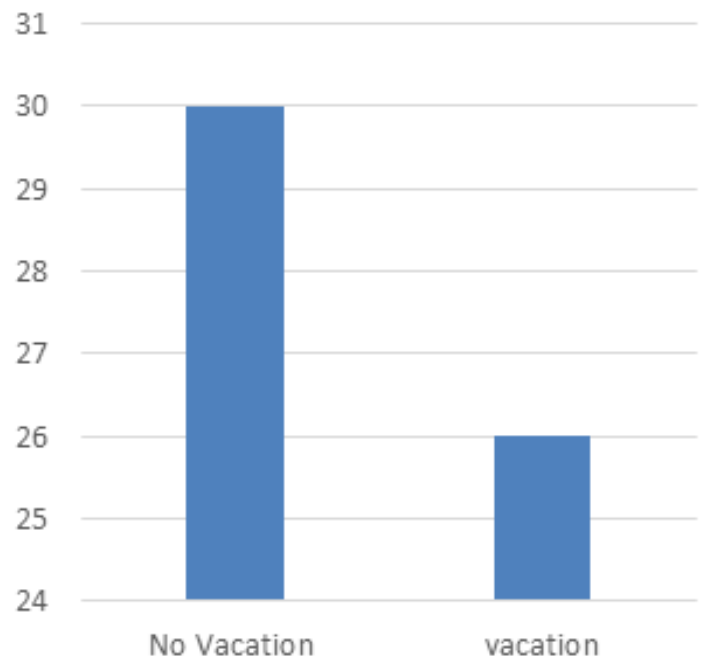

Fig. 4. Figure 4 The Average Age of Household. Source : Susenas 2013

Years of schooling also has positive effect on the probability of household to go on vacation. If years of schooling increase 1 year than the probability of going on vacation will increase 0,00233 percentage point. The longer the head of the household attend school than they higher opportunity in owning a better job and higher income. The ability increases and so the probability to go on vacation also increase.

Households who live in Sumatra and Java have higher probability to go on vacation rather than in other region. The probability of Household who live in Java is 0.0176 and Sumatera is 0.0094 . The probability to go on vacation tends to fall for household who live in Kalimantan, Sulawesi and Maluku is smaller. Household living in Maluku has the lowest probabily.

Household headed by man have lower probability to go on vacation then those headed by women. If head of the family is a man then probability of vacation is lower by 0.007464 percentage point. This is a quite interesting finding. Gender studies stated that women tend to be more sensitive and gentle in making harmony in the family. As household heads, women tend to be more vulnerable and poor. But they tend to be aweare and more less self centered oriented then men. These characteristics will make women more aware and willing to listen to their household member want's, i.e. going on vacation (Jacobsen, 1994).
TABLE I. PROBIT REGRESSION OUTPUT

\begin{tabular}{|c|c|c|c|}
\hline $\begin{array}{l}\text { Dependent: } \\
\text { Dummy } \\
\text { Vacation }\end{array}$ & Coef. & $\begin{array}{l}\text { Robust } \\
\text { Std. Error }\end{array}$ & $\begin{array}{ll}\text { Marginal } & \text { effect } \\
\text { after } & \text { probit } \\
(\mathrm{dy} / \mathrm{dx}) & \\
\end{array}$ \\
\hline Years & & & \multirow{3}{*}{$\begin{array}{l}.0023378 \\
.0062947\end{array}$} \\
\hline Schooling & $0,0467 * * *$ & 0,0036 & \\
\hline Ln income & $0,1258^{* * * *}$ & 0,0206 & \\
\hline Age & 0,0119 & 0,0063 & \multirow{3}{*}{$\begin{array}{l}.0005969 \\
-.0000107\end{array}$} \\
\hline & & & \\
\hline $\mathrm{Age}^{2}$ & $-0,0002 * *$ & 0,0001 & \\
\hline Gender & $-0,1415 * * *$ & 0,0267 & -.0074643 \\
\hline Sumatera & $0,1707 * * *$ & 0,0448 & .0094929 \\
\hline Java & 0,3723 *** & 0,0429 & .0176176 \\
\hline Kalimantan & $-0,0479$ & 0,0539 & -.0022964 \\
\hline Sulawesi & $-0,1086^{*}$ & 0,0530 & \multirow{2}{*}{$\begin{array}{l}-.0049408 \\
-.0145712\end{array}$} \\
\hline Maluku & $-0,4539 * * *$ & 0,1152 & \\
\hline Contant & $-4,4374 * * *$ & 0,2699 & \\
\hline
\end{tabular}

Results show that age has a positive influence on the probability to go on vacation, although the results were not significant. The younger the household head, the greater the probability to go on vacation. The average age of household head is 26 years old. The peak age of the household who going on vacationis 28 years old. Dimishing of probability to go on vacation occurs when the age of household head is over 28 years. Generally, when the age of household head is over 28 years old they have more family burden. They have to allocate their income to fullfill their basic, secondary and tertier need. When income relatively constant they give priority to basic need rather than tertier needs. So the probability of household to go on vacation will decrease.

\section{CONCLUSION}

Result of the findings shows that household with the characteristic: has high income, with high educatin head of household younger ( 28 years old), women, living in Jawa has the higest probability to go on vacation. Education has great leverage to incrase and stimulate household to go on vacation. People that are well educated are more exposed to all sorts of information, namely the importance of leisure and places to go on vacation. Income also plays a great deal in probability to go on vacation. Income as a proxy of avordability of the household. Through information on types of accomodation and transportation, household could find places that suits their budget.

Household living in outside of Jawa have lower propensity to go on Vacation. Many tourism sites and amusement parks are resided in Jawa. Building more tourism attarction that matches various types of tourist could induce household outside of Jawa to travel. Jawa has better infrastructur that other Islands. The recent goverment has noticed this and planned to build infrastructure that not only support the tourism sector, but also support economic growth. This economic growth will also lead to higher avordability of the population. That in the end will also increase the avordability tp go on 
vacation. Household that are young, will have higher probability to travel. Providing tourism sites that pay attention or has age targets will encourage households to go on vacation. Not every tourism sites must fullfill and provide for all cohots, but must specialised to those they cater.

\section{REFERENCES}

Jacobson, Joyce P. (1994). The Economics of Gender. Oxford, Blackwell.

Kattiyapornpong, Uraiporn, \& Kenneth E.M. (2008). Socio-demographic constraints to travel behavior. International Journal of Culture, Tourism and Hospitality Research, 3 (3).

Mc Kinsey Global Institute. (2012). The Archipelago Economy: Unleashing Indonesia's Potential. Mc Kinsey Global Institute Inc.

. (2012). The New Indonesian Consumer. Mc Kinsey Global Institute Inc.

McWhinney, James. (2016). 6 Signs You've Made It To Middle Class, http://www.investopedia.com/articles/pf/10/middleclass.asp

Mullins, Ryan R. M, Michael .A., Son K. L., Zachary R. H., \& Jeffrey P. B. (2014). Know Your Customer: How Salesperson Perceptions of Customer.

Nicolau, J.L, \& Francisco J. M. (2005). Simoutaneous Analysis of The Decisions to Go on Holiday and Vacation Expenditures. https://dialnet.unirioja.es/descarga/articulo/2471384.pdf.

Pyndick. (2012). Microeconomics. New York. McGraw Hill.

Relationship Quality Form and Influence Account ProfitabilityJournal of Marketing, (78) (November 2014), 38-58. http://dx.doi.org/10.1509/jm.13.0300.

World Economic Forum. (2015). Insight Report: The Travel and Tourism Competitiveness Report 2015, Geneva, Growth through Shocks.

Venkatesh, Alladi. (1990). Changing Consumption Patterns,in: RobKling, Spencer Olin, and Mark Poster (eds.). Postsuburban California: The Transformation of Orange County Since World War II, 1990, 142-163. 